\title{
Dollarization Persistence and Individual Heterogeneity
}

\author{
Paul Castillo* y Diego Winkelried** \\ * London School of Economics y Banco Central de Reserva del Perú \\ ** St John's College, University of Cambridge
}

\author{
DT. N ${ }^{\circ} 2007-004$ \\ Serie de Documentos de Trabajo \\ Working Paper series \\ Marzo 2007
}

\begin{abstract}
Los puntos de vista expresados en este documento de trabajo corresponden a los de los autores y no reflejan necesariamente la posición del Banco Central de Reserva del Perú.
\end{abstract}




\title{
Dollarization Persistence and Individual Heterogeneity*
}

\author{
Paul Castillo \\ London School of Economics \& \\ Central Bank of Peru \\ Jr. Miroquesada 441, Lima 1, Peru \\ pcastillob@bcrp.gob.pe
}

\author{
Diego Winkelried ${ }^{\dagger}$ \\ St John's College, \\ University of Cambridge \\ CB2 1TP, Cambridge, UK \\ dw295@cam.ac.uk
}

August 28, 2006

\begin{abstract}
The most salient feature of financial dollarization, and the one that causes more concern to policymakers, is its persistence: even after successful macroeconomic stabilizations, dollarization ratios often remain high. In this paper we claim that this persistence is connected to the fact that the participants in the dollar deposit market are fairly heterogenous, and so is the way they form their optimal currency portfolio. We develop a simple model when agents differ in their ability to process information, which turns out to be enough to generate persistence upon aggregation. We find empirical support for this claim with data from three Latin American countries and Poland.
\end{abstract}

Keywords : Dollarization, individual heterogeneity, persistence, aggregation.

JEL Codes : C43, E50, F30.

\footnotetext{
*We would like to thank Kosuke Aoki for his valuable advice. We are also grateful to Tomasz Wieladek, Bernardo Guimaraes and seminar participants at the Central Bank of Peru and at the University of Cambridge for helpful comments on earlier versions of this paper. The views expressed herein are those of the authors. Diego Winkelried gratefully acknowledges financial assistance from the ORS award and the Gates Cambridge Trust.

†Corresponding author: ++ 447765574055.
} 


\section{Motivation}

Even though dollarization is a relatively new research area, the experiences of many Latin American and transition economies during the 1990's has inspired a growing and rich body of related literature. ${ }^{1}$ Dollarization is normally associated with the partial substitution of the domestic currency by a foreign currency (the US dollar) as a store of value, as opposed to currency substitution which refers to the use of the foreign currency as a medium of exchange.

In this paper dollarization means deposit dollarization ${ }^{2}$ which leads eventually to credit dollarization and to the vulnerability of the financial system of highly dollarized countries. As stressed by Cook (2004) and Céspedes et. al (2004), the efficacy of monetary policy in small open economies with flexible exchange rates is compromised by the negative balance sheet effects generated by dollarization. In this case, sudden real depreciations can have detrimental consequences on the economic activity by reducing the net worth of firms and generating adverse effects on investment. This situation gives a rationale for a "fear of floating" behavior of central banks (Calvo and Reinhart, 2002; Morón and Winkelried, 2005).

One of the most salient features of dollarization, and probably the one that causes more concern to policymakers, is its persistence. It is well documented that dollarization increases sharply during episodes of unduly macroeconomic instability and that it remains stubbornly high even after successful stabilizations. ${ }^{3}$ A top-of-mind explanation of the hysteresis is lack of confidence in domestic currency assets as a result of the traumas brought by past inflation, devaluations, banking crises, and so on. This, however, is not very consistent with the strong macroeconomic fundamentals observed in several highly dollarized countries (e.g., Peru in the early 2000's).

An alternative avenue to address this puzzle is to adapt the existing currency substitution literature

\footnotetext{
${ }^{1}$ See De Nicoló et. al (2005), Levy Yeyati (2006) and the references therein.

2 This is also known as asset substitution (Reinhart et. al, 2003) or financial dollarization (Ize and Levy Yeyati, 2003).

${ }^{3}$ See Guidotti and Rodríguez (1992), Savastano (1996), Quispe (2000) and Kamin and Ericsson (2003).
} 
based on adjustment costs or network externalities. Guidotti and Rodríguez (1992), Sturzenegger (1997) and Uribe (1997) develop models where the cost of using the dollar for transactions depends negatively on the aggregate currency substitution ratio, so once transactions get dollarized, there is no benefit to switch back to using domestic currency if others continue using dollars. An obvious limitation is that this approach refers to the medium-of-exchange and not to the store-of-value function of money. Moreover, these models rely heavily on a knowledge stock that drives the persistence (a "ratchet variable"), so even though they can explain upward trends in the depth of dollarization, they are not useful in explaining how to dedollarize, as this may imply an implausible reduction in the knowledge stock.

Ize and Levy Yeyati (2003) provide a different framework for modelling dollarization. They derive a minimum variance portfolio (MVP) that depends on the relative volatility of inflation and real depreciation rates. Dollarization would persist even when inflation is low and stable insofar as the real depreciation volatility is smaller than that of inflation. However, this framework is static whereas persistence is inherently a dynamic phenomenon. In our view, the MVP approach which is by now very popular and has proven successful in explaining cross-sectional variation of dollarization levels, ${ }^{4}$ was not designed to deal with dynamics since the MVP, the underlying equilibrium level of dollarization, depends on unconditional moments. ${ }^{5}$

Curiously, a fact that researchers have apparently overlooked is the very nature of the participants of the dollar deposit market in dollarized economies: depositors are extremely heterogenous, ranging from large entrepreneurs to small firms to non-profit organizations and to individuals (rich and

\footnotetext{
${ }^{4}$ Ize and Levy Yeyati (2003) provide empirical evidence that the MVP has some explanatory power for the average level of dollarization across countries. De Nicoló et. al (2005) extends this empirical analysis by considering a broader set of countries.

${ }^{5}$ Dollarization hysteresis is observed in several countries with high real exchange rate volatility, e.g. Russia. The reason of this apparent contradiction with the portfolio approach may be that it is very difficult to get a sound estimate of the unconditional variances that compose the MVP.
} 
not-so-wealthy). ${ }^{6}$ Participation costs in the dollar market are virtually nil due to liberalization, deregulation and, importantly, due to the emergence of informal currency traders - known as cambistas in many Latin American countries - which benefit from buying and selling dollars with tighter markups than those in the banking sector. ${ }^{7}$ A typical cambista would hold a limited amount of money for business (say, between US $\$ 2,000$ and US\$5,000) as she is aimed to meet the dollar demand for individuals or small firms, normally unwilling to pay the higher bank premium to get their savings dollarized. ${ }^{8}$ As a result, participation becomes independent of the scale of the transaction and hence widespread.

The aim of this paper is to draw the attention to the fact that heterogeneity of depositors can easily explain the persistence of financial dollarization. As pointed out by Granger (1980), differences in individual dynamics lead to aggregate persistence. Thus, as it is reasonable to expect that the dynamics of the optimal currency portfolio of a financial expert differs from that of a blacksmith, a persistent aggregate dollarization ratio arises naturally. There are of course various differences between a financial expert and a blacksmith, but provided that both access the dollar deposit market almost for free, the relevant difference to our analysis centers in their ability to process information and, therefore, to take informed portfolio decisions. ${ }^{9}$

The rest of the paper is organized as follows. In section 2 we briefly explore these issues using Peruvian and Polish data. ${ }^{10}$ For reasons explained below, these cases illustrate nicely our claim about the interplay between individual heterogeneity and aggregate persistence. Besides, it gives us an idea of how the dollar deposit markets in representative countries are shared among various types

\footnotetext{
${ }^{6}$ An exception is Sturzenegger (1997) who studies the implications of income inequality on currency substitution, yet with no reference to deposit dollarization.

${ }^{7}$ Agénor and Haque (1996) provide an account of informal currency markets.

${ }^{8}$ Even large firms may find it profitable to trade with a pool of (well-organized) cambistas.

${ }^{9}$ Surely, income differences can also be important if the income gap between the financial expert and the blacksmith is wide. However, we find that in dollarized economies the dollar deposit participation of (many) firms and (a lot of) individuals can be taken roughly as having the same importance.

10 The figures used in section 2 come from the Central Bank of Peru and the National Bank of Poland. The facts discussed there are recorded in the annual reports of these institutions.
} 
of depositors.

In section 3 we develop a stylized model where agents face noisy information and differ in their ability to forecast when taking portfolio decisions. An important result from this setup is that the dynamics of the individual's optimal portfolio depends on her prediction errors of future dollar returns. It turns out that it is optimal for agents to be cautious when modifying the currency composition of their deposits as there is uncertainty on the quality of the data agents receive. This caution is reflected in portfolios that may adjust in a relatively slow fashion. Finally, we show that upon aggregation of the individual dollarization decisions it is possible to generate a very persistent economy-wide dollarization ratio. ${ }^{11}$

In section 4 we test the empirical hypotheses of the theoretical model and find supportive evidence from aggregate data of three Latin American countries and Poland. The results suggest that the distributions of "forecasting abilities" behind the aggregate dollarization ratios are very spread and skewed. We regard this result as consistent with the idea of financial experts sharing the dollar market with blacksmiths that save in dollars. In section 5 we discuss possible extensions to the analysis. Section 6 concludes and gives policy recommendations. Derivations and complementary results are shown in the appendix.

\section{Two illustrative cases}

As documented by Savastano (1996), dollarization emerges progressively in response to macroeconomic instability, particularly high levels of inflation, showing a well-defined pattern: first agents replace domestic currency as reserve of value, holding usually dollars outside the financial

${ }^{11}$ Our approach is related to other branches of the literature. For instance, Lewbel (1994) uses aggregate information to test heterogeneity on consumption dynamics whereas Michelacci (2004) explains the high degree of persistence of output with the cross-sectional heterogeneity of productive firms. 
system ("under the mattress"). Then, the dollar is used in some transactions, typically involving real estates and durable goods, and eventually some prices are set in dollars. Most governments later on allow banks to issue deposits in foreign currency to avoid financial disintermediation. ${ }^{12}$ The actual experience of various countries shows that within a year an economy can increase its dollarization ratio enormously, see Figures 1(a) and 2(a).

On the other side, episodes of dedollarization (i.e., a sustained reduction in the dollarization ratio) are not very common and thus there is no well-established pattern in the literature. Yet, if ever happened, the dedollarization process is likely to be slow. The analysis of these events, as opposed to the increase of dollarization, provide very useful information about the way different depositors decide the currency composition of their savings and on how they respond to news coming from the macroeconomic environment.

\subsection{Peru in the early 2000's}

Although the Peruvian dollarization experience shares various of the aforementioned features, it has its own appeal. ${ }^{13}$ As shown in Figure 1(a), in 1991 (after a four-digit hyperinflation in 1990) the ratio was $60 \%$ and has remained fluctuating roughly between $65 \%$ and $70 \%$ for a decade. Since 2000 , it has shown a sustained reduction to about $50 \%$ in 2005 . Of course, $50 \%$ is still a big number, but there are some interesting facts behind this recent drop.

There are at least two forces driving this decrease. Firstly, after 8 years of announcing inflation targets within a monetary targeting regime (since 1994) and after 5 years of having achieved a onedigit inflation rate, the Central Bank announced the adoption of a fully fledged inflation targeting regime in 2002. This has helped to anchor inflation expectations and has reduced inflation and

12 See also Kamin and Ericsson (2003), De Nicoló et. al (2005) and Levy Yeyati (2006).

${ }^{13}$ See Quispe (2000) for a careful historical account of the dollarization experience in Peru. 
nominal interest rate volatility. Secondly, between 2001 and 2005, the nominal and real exchange rates have appreciated $(6.2 \%$ and $5.1 \%)$ as a result of a very favorable foreign environment: increasing terms of trade leading to an export boom and very low international interest rates. In a nutshell, the real return to holding deposits dollars vis-à-vis holding deposits in domestic currency has fallen considerably in the early 2000's.

Figure 1(b) shows deposit dollarization by type of deposit: demand, savings and a breakdown of time deposits in certificates, "CTS" and others. A glimpse of the figure reveals that both demand and "CTS" deposits have not reacted to the recent change in the dollar real return trend. Demand deposits accounts for about $20 \%$ of total deposits and as the most liquid, almost transactional kind of deposit the flat pattern is justified. On the other side, the CTS is the Peruvian version of an unemployment insurance; by law, it is hold exclusively by individuals and can be claimed only when an individual becomes unemployed. The CTS deposits have reacted even less than the demand deposits, which is puzzling.

The figure also shows a moderate downward trend in the savings and other time deposits. About $80 \%$ of the saving and roughly half of the other time deposits are held by individuals. From 2001 to 2005 both ratios have decreased in about $10 \%$. What is remarkable from Figure 1(b) is the strong reaction of the certificate of deposits ratio which has fallen in almost $40 \%$, and with no doubts is driving the fall in the aggregate ratio of Figure 1(a). The interesting fact is that although the certificate of deposits have similar term than the CTS and the other time deposits, they are mainly held by firms and not individuals.

\subsection{Poland towards a market economy}

The Polish experience is regarded as the most successful shift from a planned to a market-oriented economy, and is a thriving example of dedollarization. By the end 1980's, Poland was on the verge 
of a profound economic crisis. The huge distortions on relative prices and the cumulative fiscal deficits, inherited from the years of central planning, induced a rapid increase in inflation that reached its historical maximum of 550 percent in 1989. In response to this unstable macroeconomic environment, dollarization ratios increased rapidly, from levels around $20 \%$ in 1985 to a peak of $60 \%$ in 1989. This is shown in Figure 2(a).

After the introduction of a series of pro-market reforms and of a stabilization program (the socalled "shock-therapy"), ${ }^{14}$ dollarization ratios dropped to averages of $40 \%$ percent by the end of 1993, hand-to-hand with the reduction of inflation (from 500\% to $36 \%$ ). As the macroeconomic conditions kept improving, additional institutional reforms were put in place. Notably, in 1997 the National Bank of Poland was granted independence and a well-defined objective: to guarantee price stability. Dollarization decreased even more reaching by 2001 the level of 18\%, comparable with that of developed European economies, as the UK.

A common feature of the Polish experience with the Peruvian one discussed above is the observed heterogeneity of dollarization dynamics among type of deposits. Figure 2(b) reveals that by the end of 1993, the difference between the dollarization ratios of households and firms was of the order of $70 \%$ for time deposit and $40 \%$ for demand deposits. These differences remained on the range of $20 \%$ for more than 4 years.

\subsection{Moral}

The differences between how individuals and firms decide their portfolio composition is obvious. Usually firms have more resources allocated to the management of their funds, whereas individuals often base their decisions on their experience, those of some neighbors and their limited access to

\footnotetext{
${ }^{14}$ A drastic series of institutional and market reforms were put in place in 1990: the government liberalized controls of almost all prices, eliminated most subsidies, abolished administrative allocation of resources in favor of trade, promoted free establishment of private businesses, liberalized the system of international economic relations, and introduced an internal currency convertibility with a currency devaluation of $32 \%$.
} 
information. Moreover, the decision-making even within firms or within individuals is likely to be dissimilar. Our brief inspection of the Peruvian and Polish experiences illustrates our main claim that these differences accounts for much heterogeneity in dollarization decisions. We next analyze how this translates into persistence.

\section{A simple model}

We use a simple framework to show how the combination of imperfect, noisy information on real returns of foreign assets, and specially the heterogeneity among market participants can generate a persistent degree of dollarization.

The model economy is populated by a number of almost identical individuals. They share the same endowment, which is normalized to one, and the same preferences, but they differ in their ability to process information and therefore in their expectations on future outcomes. ${ }^{15}$

Every period agents choose the composition of their portfolio between two assets, one that offers a fixed real return $R^{P}$ which is denominated in domestic currency (pesos from now on) and the other denominated in dollars with real return $R_{t}^{D}$. The real ex-ante excess of return of the dollar over the pesos asset is simply $R_{t}=R_{t}^{D}-R^{P}$.

\subsection{Portfolio decision}

Depositors are risk adverse. Individual $i$ devotes an amount $x_{i t}$ of her savings to the dollar asset and the remaining $1-x_{i t}$ to purchase the asset in pesos. We follow Ize and Levy Yeyati (2003) in postulating a standard mean-variance utility function. The portfolio decision is ex-ante and based on

\footnotetext{
15 Our analysis hold for agents with heterogenous endowments, i.e. wealth/income inequality, as long as they are correlated with the abilities to process information. See appendix $\mathrm{C}$ for details.
} 
imperfect information on real returns, so utility for individual $i$ is defined in terms of the conditional expectation for period $t+1$ with information up to period $t,{ }^{16}$

$$
\begin{aligned}
U_{i t} & =E_{t}\left[x_{i t} R_{t+1}^{D}+\left(1-x_{i t}\right) R^{P}\right]-0.5 \operatorname{var}_{t}\left(x_{i t} R_{t+1}^{D}+\left(1-x_{i t}\right) R^{P}\right) \\
& =E_{t}\left[x_{i t} R_{t+1}+R^{P}\right]-0.5 \operatorname{var}_{t}\left(x_{i t} R_{t+1}\right)=x_{i t} \hat{r}_{i t+1}+R^{P}-0.5\left(x_{i t}\right)^{2} v_{i t+1}
\end{aligned}
$$

where $\hat{r}_{i t+1}$ and $v_{i t+1}$ are the mean and variance of the excess return $R_{t}$ that individual $i$ expects for period $t+1$, conditional on information up to period $t$.

The value of $x_{i t}$ that maximizes (1) is

$$
x_{i t}=\frac{\hat{r}_{i t+1}}{v_{i t+1}}
$$

Thus, agents will increase their dollar deposits when they expect a higher real return on this asset for the same expected variance, or when the expect a lower variance given a level of excess of returns.

\subsection{Forecasting}

As equation (2) reveals, the only relevant pieces of information for portfolio decisions are the exante excess return and its variance. To make things easier, consider that each agent focuses directly on forecasting $R_{t}$, and not on forecasting its components $\left(R_{t}^{D}\right.$ or $R^{P}$, which may imply forecasting inflation, depreciation, confiscation risk and so on), and assume that $R_{t}$ follows a general $\mathrm{AR}(1)$ process

$$
R_{t+1}=\mu(1-\alpha)+\alpha R_{t}+w_{t+1} \quad w_{t} \sim \operatorname{iid}\left(0, \sigma_{w}^{2}\right)
$$

\footnotetext{
${ }^{16}$ We have imposed a value of one to the risk aversion parameter in the utility function. This assumption is harmless to our results.
} 
In period $t$, the excess return $R_{t}$ cannot be perfectly observed. What agents observe is an idiosyncratic noise-ridden version of $R_{t}, S_{i t}=R_{t}+\varepsilon_{i t}$ where $\varepsilon_{i t} \sim i i d\left(0, \sigma_{\varepsilon i}^{2}\right)$. Our assumption that agents receive different signals can be easily rationalized as a reduced form of a problem where agents face a common signal, but they have different capacity for processing aggregate information. As in Sims (2003), when agents face limited capacity for processing information, they would choose optimally how much effort to allocate in certain activities, as portfolio management. Since individuals face different resources and capacity constraints, when agents have to invest real resources to increase its capacity for processing information on management activities - for instance, to learn how to read and interpret financial news - they can rationally choose to allocate different capacity for processing information on this activity, therefore agents would eventually face different signals.

Each individual has a forecasting model of the form

$$
\begin{array}{lll}
R_{t+1}=\mu(1-\alpha)+\alpha R_{t}+w_{t+1} & & w_{t} \sim \operatorname{iid}\left(0, \sigma_{w}^{2}\right) \\
S_{i t} & =R_{t}+\varepsilon_{i t} & \varepsilon_{i t} \sim \operatorname{iid}\left(0, \sigma_{\varepsilon i}^{2}\right)
\end{array}
$$

Since $S_{i t}$ is a noisy indicator, individual $i$ has first to extract $R_{t}$ from $S_{i t}$ (i.e., "nowcasting") and then forecast its mean and variance to implement (2). Define $q_{i}=\sigma_{w}^{2} / \sigma_{\varepsilon i}^{2}$ as signal-to-noise ratio which plays a key role in determining how the noisy observations are weighted for signal extraction and prediction. The higher is $q_{i}$ the more past observations are discounted in forecasting the future. As it can be seen from (4), each individual is given a value of $q_{i}$ to perform her predictions, and this value alone determines the whole forecasting model. This is the only source of (crosssectional) heterogeneity in this setup. Everything else $-\alpha, \mu, \sigma_{w}^{2}$ and the process (3) - is of common knowledge across individuals.

That individuals are heterogenous in their ability to extract information from they signal rationalizes 
in a simple manner the fact that those with high $q_{i}$ (the financial experts) are able to extract more information from the noisy indicator $S_{i t}$ than those with low $q_{i}$ (the blacksmiths). In contrast to the latter, the former might be able to distinguish whether changes in $S_{i t}$ reveal underlying movements in $R_{t}$ or are just due to noise. This in turn implies differences in the speed in which short-run forecasts are adjusted as new information becomes available, and translates directly to portfolio differences among market participants. We interpret this heterogeneity as differences in the ability people have to forecast.

Define $v_{i t}=E_{t}\left[\left(R_{t}-\hat{r}_{i t}\right)^{2}\right]$ as the mean squared error (MSE) of the predictor $\hat{r}_{i t}$. Standard results from the signal extraction literature lead us to the optimal prediction rule ${ }^{17}$

$$
\hat{r}_{i t+1}=\mu(1-\alpha)+\alpha \hat{r}_{i t}+k_{i t}\left(S_{i t}-\hat{r}_{i t}\right)=\mu(1-\alpha)+\left(\alpha-k_{i t}\right) \hat{r}_{i t}+k_{i t} S_{i t}
$$

where the forecasted value of $R_{t}$ for next period is the projection of today's forecasted value plus a correction, an updating that is proportional to the latest prediction error incurred $\left(S_{i t}-\hat{r}_{i t}\right) .{ }^{18}$ The value of $k_{i t}$, the Kalman gain, is given by the (adjusted) ratio of the MSE of $\hat{r}_{i t}$ to the variance of the noisy indicator,

$$
k_{i t}=\alpha\left(\frac{v_{i t}}{v_{i t}+\sigma_{\varepsilon i}^{2}}\right)
$$

The MSE of $\hat{r}_{i t}$ evolves according to the following recursion

$$
v_{i t+1}=\frac{v_{i t}\left(\alpha^{2} \sigma_{\varepsilon i}^{2}+\sigma_{w}^{2}\right)+\sigma_{\varepsilon i}^{2} \sigma_{w}^{2}}{v_{i t}+\sigma_{\varepsilon i}^{2}}
$$

17 The reader that is familiar with state-space modeling will note that the recursions (5) and (7) below are straightforward applications of the Kalman filter. See Ljungqvist and Sargent (2000, ch. 2 and ch. 21) and Harvey and De Rossi (2006) for further details.

${ }^{18}$ It is important to emphasize that $\hat{r}_{i t}$ represents the best forecast of $R_{t}$ conditional on information up to period $t-1$. Since portfolio decisions are to be taken one period in advance, they do not incorporate the information contained on the signal $S_{i t}$, but this information is taken into account to improve the next period's forecast of $R_{t+1}$. 
For expositional convenience define $\tilde{v}_{i t}=v_{i t} \sigma_{\varepsilon i}^{-2}$. Then, (7) becomes

$$
\tilde{v}_{i t+1}=\frac{\tilde{v}_{i t}\left(\alpha^{2}+q_{i}\right)+q_{i}}{\tilde{v}_{i t}+1}
$$

It is clear from equation (8) that $\tilde{v}_{i \tau+1}=f\left(\tilde{v}_{i \tau}\right)$. There is a fixed point such that $\tilde{v}_{i}=f\left(\tilde{v}_{i}\right)^{19}$ and moreover, since $f^{\prime}\left(\tilde{v}_{i}\right)<1$ it is globally stable: regardless of the initial condition $\tilde{v}_{i 0}$ we have that $\tilde{v}_{i \tau} \rightarrow \tilde{v}_{i}$ and consequently $k_{i \tau} \rightarrow k_{i}=\alpha \tilde{v}_{i}\left(\tilde{v}_{i}+1\right)^{-1}$ as $\tau \rightarrow \infty$. This means that as $\tau$ becomes larger, i.e. as each individual has performed the signal extraction exercise a number of times, the updating process defined in (5) and (7) converges to an equilibrium rule. ${ }^{20}$ If it is assumed that this recursive process was initialized long before period $t$ then $\tilde{v}_{i t}\left(\right.$ or $v_{i t}$ ) and $k_{i t}$ can be safely treated as constants that depends on $q_{i}$. This fact simplifies the calculations considerably without compromising our conclusions.

To have a better grasp of the way heterogeneity among agents affects their forecasts (and portfolios), assume for a moment that $\alpha \rightarrow 1$ and solve (5) recursively to get

$$
\hat{r}_{i t+1}=k_{i} \sum_{j=0}^{\infty}\left(1-k_{i}\right)^{j} S_{i t-j}
$$

It is clear from this geometrically distributed lag expression that different draws of $q_{i}$ (and hence of $k_{i}$ ) are associated with different ways of weighting the available information (the noisy indicators up to period $t$ ) in order to produce a forecast. ${ }^{21}$

\footnotetext{
19 The fixed point is the positive root of $\tilde{v}_{i}^{2}+\left[\left(1-\alpha^{2}\right)-q_{i}\right] \tilde{v}_{i}-q_{i}=0$.

${ }^{20}$ Convergence is monotonic $\left(\tilde{v}_{i \tau} \geq \tilde{v}_{i \tau+1} \geq \tilde{v}_{i}\right)$ because $v_{i \tau+1}$ is based on more information than $v_{i \tau}$.

21 As noted in Harvey (1989, ch. 4), the forecasting model converges to the popular Exponential Smoothing method (ES) if $\alpha \rightarrow 1$. However, the scheme explained here is optimal in the sense that it minimizes the one step ahead MSE, whereas ES is basically ad hoc.
} 


\subsection{Individual dynamics}

Using the fact that $v_{i t} \rightarrow v_{i}, k_{i t} \rightarrow k_{i}$ and the optimal updating/forecasting rule (5), the optimal dollar investment (2) boils down to

$$
x_{i t}=\frac{\hat{r}_{i t+1}}{v_{i t+1}}=\frac{\hat{r}_{i t+1}}{v_{i}}=\frac{\mu(1-\alpha)}{v_{i}}+\left(\alpha-k_{i}\right)\left(\frac{\hat{r}_{i t}}{v_{i}}\right)+\left(\frac{k_{i}}{v_{i}}\right) S_{i t}
$$

After plugging (5) into (9), we get

$$
x_{i t}=a_{i} x_{i t-1}+c_{i}+b_{i} S_{i t}
$$

where $a_{i}=\left(\alpha-k_{i}\right), c_{i}=\mu(1-\alpha) v_{i}^{-1}$ and $b_{i}=\left(\tilde{v}_{i}+1\right)^{-1}$. The individual's dollarization ratio follows an autoregressive process and, as such, exhibits some degree of persistence that depends on $k_{i}$. It is easy to show that $k_{i}$ is increasing in $q_{i}$, which implies that the individuals with higher $q_{i}$ (those who gain more information from the signal each period) have less persistent dollarization ratios. As (10) shows, the higher the $k_{i}$, the lower the degree of persistence of dollarization ratios. Furthermore, individuals with low $q_{i}$ will tend to consider the dollar asset as less risky, since they would attach a higher fraction of the variance of the signal to the noise and not to real excess return.

The dynamics of individual dollarization decisions shows that with noisy signals of returns, individuals have to rely on past information to optimally forecast them, and have to react with caution to news. To the extent that past portfolio decisions contain past information of returns, it becomes optimal for individuals to make their dollarization ratios depended on past dollarization ratios. ${ }^{22}$ Thus, our simple model shows that noisy information can render not only persistence but

\footnotetext{
22 A similar result but in a different setup can be found in Aoki (2003). In that paper the central bank sets interest rates in an environment with noisy information on output and inflation. The optimal policy rule implies some persistence coming from the cautiousness that the lack of perfect information demands.
} 
also an higher individual dollarization ratio.

\subsection{Aggregate dynamics}

In a static world the effects of aggregation are well-known: it tends to smooth away individual erratic movements and to fill in discontinuities that may be present at the disaggregate level. Within a dynamic framework, aggregation also increases persistence. ${ }^{23}$ To see why consider a group of individuals who hold a small amount of the dollar asset and face an aggregate shock that makes it more attractive (e.g., a strong real depreciation). According to (10), these individuals will increase their dollar holdings immediately. But then, they will also revise their expectations about future returns in favor of the dollar asset, thereby perpetuating the impact effect of the shock on aggregate dollarization. Thus, the moderate persistence in the individual portfolio formation due to the lack of perfect information, summarized in equation (10), is exacerbated by aggregation. ${ }^{24}$

Consider that $q_{i}$ is drawn from a distribution such that the cdf of $a_{i}$ is $F(a)$. To better understand the workings of aggregation and how aggregate data can help us to draw conclusions about the underlying heterogeneity in dollarization decisions, it is convenient to focus for a moment on the case where the individuals signals, $S_{i t}$, are iid sequences. We then relax this assumption.

\subsubsection{Aggregation when signals are $i i d$}

Appendix A shows that aggregation of (10) across the distribution of $a_{i}$ renders the following process for the economy-wide dollarization ratio $X_{t}$,

$$
X_{t}=\sum_{j=1}^{\infty} A_{j} X_{t-j}+\tilde{C}+\tilde{U}_{t}
$$

\footnotetext{
23 The classic reference for the econometrics of this effect is Granger (1980), which assumes that $F(a)$ (defined below) is a Beta distribution. See also Pesaran (2003) and Zaffaroni (2004) for recent developments.

24 See Michelacci (2004) for a similar analysis.
} 
where the $A_{j}(j=1,2, \ldots)$ are coefficients, $\tilde{C}$ is a constant and $\tilde{U}_{t}$ is an aggregate serially uncorrelated disturbance. As suggested before, the remarkable fact is that although at the individual level the dollar share in the portfolio follows an $\mathrm{AR}(1)$ process, it becomes $\mathrm{AR}(\infty)$ at the aggregate - usually known as a process exhibiting long-memory.

As stressed by Lewbel (1994), the coefficients in (11) are tightly related to the shape of $F(a)$. In appendix A it is also shown that they satisfy the recursion

$$
A_{s}=m_{s}-\sum_{j=1}^{s-1} m_{s-j} A_{j} \quad \text { for } s=1,2, \ldots
$$

where $m_{s}$ is the $s$-th moment of the distribution of $a_{i}, m_{s}=\int a^{s} \mathrm{~d} F(a)$. Hence, it is easy to verify that

$$
\begin{aligned}
\operatorname{mean}(a) & =m_{1}=A_{1} \\
\operatorname{variance}(a) & =m_{2}-m_{1}^{2}=A_{2} \\
\operatorname{skewness}(a) & =\left(m_{3}-3 m_{1} m_{2}+2 m_{1}^{3}\right)\left(m_{2}-m_{1}^{2}\right)^{-3 / 2}=\left(A_{3}-A_{1} A_{2}\right)\left(A_{2}\right)^{-3 / 2}
\end{aligned}
$$

These relations allow us to determine how the distribution of forecasting abilities affects persistence at the aggregate level. The higher $A_{1}$, the higher the mean which implies that the average individual has herself a more persistent behavior, rendering subsequently a more persistent $X_{t}$. On the other side and strikingly, a higher $A_{2}$ renders also more persistence: the higher the heterogeneity among individuals, the more persistent the aggregate dollarization ratio. Finally, as pointed out by Zaffaroni (2004), the low frequency behavior of the aggregate is determined by the shape of the cross sectional distribution as $a_{i} \rightarrow 1^{-}$. Hence, a distribution with a heavy left tail $\left(A_{3}<A_{1} A_{2}\right)$, which indicates a higher mass of persistent individuals $\left(a_{i} \approx 1\right)$, would suggest higher aggregate persistence.

It is now clear that this framework can be tested straightforwardly. If the estimates of $A_{s}$ using aggregate data are inconsistent with the notion of various dynamic processes that have been 
aggregated into (11), then we are to reject the model. ${ }^{25}$ The most obvious symptoms of contradiction would be a non-positive estimate of $A_{2}$, the variance of $a_{i},{ }^{26}$ or a very negative value for $A_{1}$, the mean.

\subsubsection{Aggregation when signals are correlated}

Recall now that $S_{i t}=R_{t}+\varepsilon_{i t}$, where $\varepsilon_{i t}$ is an idiosyncratic shock. Then, the aggregation of (9) (see appendix A) leads to

$$
X_{t}=\sum_{j=1}^{\infty} A_{j} X_{t-j}+\sum_{r=0}^{\infty} B_{j} R_{t-j}+\hat{C}+\hat{U}_{t}
$$

which as opposed to (11) includes a distributed lag of $R_{t}$. This difference is clearly a consequence of postulating different assumptions about the nature of $S_{i t}$. Yet, the coefficients $A_{s}(s=1,2, \ldots)$ have the same interpretation and implications as before.

\section{Empirical evidence}

This section tests whether the dynamics of the aggregate dollarization ratio in selected countries can be regarded as coming from the aggregation of heterogeneous depositors. It is important to bear in mind that the amount of information about individual behavior that can be inferred from aggregate data, as we attempt to do below, is unquestionably limited. Different assumptions regarding individual decisions can be found to be consistent with a given observed aggregate variable. Yet, the facts reported below are supportive to the main hypothesis of this paper and the predictions of the theoretical model.

\footnotetext{
25 Or the assumptions behind the aggregation, see appendix A.

${ }^{26}$ Note that $A_{2}=0$ implies a degenerate distribution of $a_{i}$ on the point $A_{1}$, i.e. a model with a representative agent or identical individuals.
} 
As discussed, the moments of the underlying distribution $F(a)$ are linked with the autoregressive coefficients $A_{s}$ in equations (11) and (13), so by estimating them we can investigate the extent of heterogeneity among participants in the dollar deposit market via the analysis of summary statistics. To compute further figures of interest, as confidence intervals, we inevitably need to impose some assumptions on $F(a)$ and parameterize it. Contemporaneous aggregation of equation (10) does not involve a specific distribution, but the microeconomic structure in section 2 indicates that $F(a)$ is truncated: it is easy to verify that $a_{i} \rightarrow 0$ (or $k_{i} \rightarrow \alpha$ ) if $q_{i} \rightarrow \infty$ and $a_{i} \rightarrow \alpha$ (or $k_{i} \rightarrow 0$ ) as $q_{i} \rightarrow 0$. Thus, to ease the interpretation of the results and to have a better grasp of the shape of the underlying $F(a)$, we map from the estimate coefficients to the moments using (12) and then map these moments to the parameters of a sufficiently flexible truncated distribution. Empirically $\alpha \approx 1$, so we focus on the support $a \in[0,1]$. A distribution that fulfills the aforementioned requirements and performs reasonably well is the (2-parameter) truncated $\log$-normal (with $\tilde{a}=1-a \in[0,1]$ in the $x$-axis to ensure the negative skewness reported below). ${ }^{27}$

\subsection{Baseline specification}

Consider equation (11). Three points are worth mentioning before presenting some results. Firstly and unsurprisingly every dollarization ratio $X_{t}$ we considered has a unit $\operatorname{root}^{28}$ and to avoid wellknown biases in the estimation of autoregressive coefficients when a unit root is present we estimate (11) in first differences,

$$
\Delta X_{t}=\sum_{j=1}^{\infty} A_{j} \Delta X_{t-j}+U_{t}^{\dagger}
$$

\footnotetext{
27 The use of this distribution renders the same cross-country comparison than a (2-parameter) Beta distribution or a (3-parameter) truncated skew-normal distribution.

${ }^{28}$ Results of unit root tests are available upon request to the authors. See also appendix B.
} 
Appendix A shows that (14) is not only the first-differenced version of (11), but is also the result of aggregating (10) after first-differentiating. Hence, the coefficients in (14) are indeed the same as in (11). The disturbance $U_{t}^{\dagger}$ is autocorrelated and heteroscedastic ${ }^{29}$ so robust inference is required.

Secondly, due to data limitations it is not possible to estimate equation (14) as it stands. Data are finite, so a truncation in the lags of the $A R(\infty)$ process is unavoidable.

Lastly, if convenient, we consider even richer dynamics than the suggested by our very stylized theoretical model by introducing a MA(1) component in (14). In practice, this fact has no other implication for our analysis than to produce better estimates of the $A_{s}$. As noted by Lewbel (1994), with a MA component present only a finite number of the moments of $F(a)$ can be recovered as an infinite autoregression in $X_{t}$ (or in $\Delta X_{t}$ ) cannot be separated from the MA parameter, say $\theta$. This is a theoretical rather than empirically substantive concern; as noted earlier, our attempt is not to recover every moment of $F(a)$, but just the first few.

We gathered information for Peru and Uruguay (two highly dollarized countries), Mexico and Poland. Data are quarterly spanning roughly from the mid-1980's to the mid-2000's. As it is customary in the dollarization literature, $X_{t}$ is measured as the ratio of foreign currency deposits from the private sector in the domestic banking system to M2. ${ }^{30}$ This information is widely available and our sources are the websites of the various central banks and the International Financial Statistics database, IFS. The regression with the shortest time series (Poland) has $N=69$ observations; the one with the largest (Peru), $N=94$.

\subsubsection{Results}

\footnotetext{
${ }^{29}$ See Pesaran (2003) for further details.

${ }^{30}$ A popular alternative definition of the dollarization ratio discriminate between residents and non-residents, which includes deposits by residents abroad (Ize and Levy Yeyati, 2003). We did not include this definition in our empirical work as the corresponding available time series are shorter for the pool of countries analyzed.
} 
For each country an $\operatorname{ARIMA}(2,1,0)$ was first fitted. Then, we test for residual autocorrelation and include further lags until the residuals appear serially uncorrelated. In every case, no more than 2 lags is needed, but in Mexico when the lag length is 4 . For robustness sake we then include a MA component in the best autoregressive specification. Table 1 reports for each country the best autoregressive model, $\operatorname{ARIMA}(2,1,1)$ or $\operatorname{ARIMA}(4,1,0)$, and the corresponding $\operatorname{ARIMA}(2,1,1)$ or $\operatorname{ARIMA}(4,1,1)$ equations. The column labelled $\theta$ contains the estimated MA coefficient. For each country we have marked our preferred specification, i.e. the more parsimonious model that describes the data sufficiently well, with a $\star$.

A finding that is robust among countries and specifications within the same country, is that the coefficients $A_{1}$ and $A_{2}$ are significantly positive. Recall that $A_{1}$ is the mean of $F(a)$ and $A_{2}$ is its variance. Besides, the estimates of the implied third central moment $A_{3}-A_{1} A_{2}$ in each country suggest that $F(a)$ is skewed to the left. Provided that $A_{1}>0$, a left-skewed $F(a)$ would be expected if it were the mixture of a mass point above the mean (relatively persistent individuals, those who change their portfolio slowly) and some individuals with $a$ close to zero (corresponding to those who change their portfolio quickly). Negative skewness, thus, is consistent with a financial expert sharing the dollar market with a non-expert blacksmith saving in dollars.

A remarkable fact from Table 1 is that the estimates for Peru are close to those of Uruguay, whereas the Mexican estimates are similar to the Polish. Recall that Peru and Uruguay are heavily dollarized (above 50\%), whereas Mexico and Poland, even though have reported sizeable dollarization ratios by the early or mid-90's, have dollarization ratios less than $30 \%$ by the end of the sample. In Peru and Uruguay the coefficients are of comparable magnitude, $A_{2} \approx A_{1}$, which means that the underlying $F(a)$ is very spread, the $a$ 's are fairly heterogeneous. ${ }^{31}$ Hence, the highly dollarized economies appear to have a spreader $F(a)$ which is consistent with the idea of decreasing participation costs as 31 These estimates imply a coefficient of variation $\sqrt{A_{2}} / A_{1}$ of 2.18 for Peru, 1.75 for Uruguay, 0.91 for Mexico and 0.71 for Poland. 
dollarization expands. Furthermore, when parameterize $F(a)$, we found the dollarized countries are more heavily skewed than Mexico and Poland. The estimate of the mass of persistent individuals, $\operatorname{Pr}(0.5 \leq a \leq 1)$, is roughly 0.85 for Peru and Uruguay and about 0.60 for Mexico and Poland.

\subsection{Augmented specification}

Consider now equation (13). In the likely case that signal $S_{i t}$ is not $i i d$, then the estimates of Table 1 may be biased due to the omission of relevant variables. Next, we augment the ARIMA models of Table 1 to investigate whether this omission changes our main conclusions.

As discussed above, the actual object to be estimated is

$$
\Delta X_{t}=\sum_{j=1}^{p_{X}} A_{j} \Delta X_{t-j}+\sum_{j=0}^{p_{R}} B_{j} \Delta R_{t-j}+U_{t}^{\ddagger}
$$

where $p_{X}$ and $p_{R}$ are finite lag lengths. The presence of $\Delta R_{t}$ and its lags in (15) follows directly from the fact that the individuals in the theoretical model base their decisions exclusively on this variable. Nonetheless, a richer modelling framework can easily extend (15) to

$$
\Delta X_{t}=\sum_{j=1}^{p_{X}} A_{j} \Delta X_{t-j}+\sum_{j=0}^{p_{R}} B_{j}^{D} \Delta R_{t-j}^{D}+\sum_{j=0}^{p_{R}} B_{j}^{P} \Delta R_{t-j}^{P}+U_{t}^{\ddagger}
$$

As $R_{t}=R_{t}^{D}-R_{t}^{P}$, equation (16) encompasses (15) which is a restricted version with $B_{s}^{D}=-B_{s}^{P}$ for every $s$. For this reason, we will focus on (16) from now on. ${ }^{32}$

An empirical issue that raises with the introduction of the real returns in the aggregate equations is, precisely, how to measure them. The "true" returns involve expectations of future macroeconomic variables, which historical data are barely available for the countries in our analysis. Call $i_{t}^{P}$ and $i_{t}^{D}$ the nominal interest rates in domestic currency and US dollars, respectively, $\delta_{t}$ the nominal depre-

\footnotetext{
32 The estimations of (15), which are similar to our purposes, are available upon request to the authors.
} 
ciation (i.e., the percent change of the nominal exchange rate, domestic currency per US dollar) and $\pi_{t}$ the CPI inflation. We entertain two measurements of the real returns:

$$
\begin{aligned}
& \text { ex-ante }: \quad R_{t}^{P}=\frac{1+i_{t}^{P}}{1+\pi_{t+1}}-1 \quad \text { ex-post }: \quad R_{t}^{P}=\frac{1+i_{t}^{P}}{1+\pi_{t}}-1 \\
& R_{t}^{D}=\frac{\left(1+i_{t}^{D}\right)\left(1+\delta_{t+1}\right)}{1+\pi_{t+1}}-1 \quad R_{t}^{D}=\frac{\left(1+i_{t}^{D}\right)\left(1+\delta_{t}\right)}{1+\pi_{t}}-1
\end{aligned}
$$

CPI and nominal exchange data are readily available. For $i_{t}^{P}$ we use the deposit rate in domestic currency for Peru, Poland and Uruguay and the saving rate in domestic currency for Mexico. For $i_{t}^{D}$, we found data on the interest rate paid to domestic deposits in dollars only in the case of Peru and Uruguay. For Mexico and Poland we approximate $i_{t}^{D}$ with the deposit rate in the US. ${ }^{33}$ Our sources are still the central banks and the IFS.

Finally, the presence of a contemporaneous return (16) may rise the possibility of endogeneity bias. We use a 2SLS procedure to estimate this equation. The instruments are listed in the note to Table 2. It is worth mentioning that OLS or the exclusion of the contemporaneous returns did not alter the main results of this robustness check. ${ }^{34}$

\subsubsection{Results}

Table 2 displays the estimation results. To save space we do not report the coefficients of the returns (as they are not of direct interest for our analysis) but do report an $F$-statistic assessing its overall significance. We set the lag length $p_{X}=3$. This is the best choice for Mexico; for the other countries, the optimal is $p_{X}=2$, but we still set $p_{X}=3$ to ensure that no autoregressive effect is ignored. The

\footnotetext{
${ }^{33}$ Unfortunately we could not find time series long enough of country risk to have a better measure of $R_{t}^{D}$ in these two countries. The estimation results, though, were robust when we considered the LIBOR rate (in US dollars, at various terms) instead of the US deposit rate.

${ }^{34}$ We did not find a significant cointegration relationship between $X_{t}, R_{t}^{P}$ and $R_{t}^{D}$ or between $X_{t}$ and $R_{t}$ to treat (16) as an error correction model. Structural breaks in our 20 year data span may explain this failure. Consistently with this, the levels of the returns did not appear to have enough explanatory power in the equations of Table 2.
} 
choice of $p_{R}$, reported in the table, responds to the minimization of the Schwarz criterion.

Recall that by estimating the augmented equations we are assessing whether the results of Table 1 are robust. So, are they robust? In general they are. A quick comparison of the estimates in Table 2 with those in Table 1 reveals that due to the presence of the returns, the fit of the various equations increases, but the estimates of $A_{1}, A_{2}$ and $A_{3}-A_{1} A_{2}$ do not change much. The notable exception to this pattern is the Mexican case when the returns are measured in the ex-post manner, as $A_{1}$ losses statistical significance. ${ }^{35}$ However, the main claim of the previous sections still holds, qualitatively and almost quantitative: the heterogeneity of decision-makers that underlies the aggregate dollarization ratios is high, and this fact leads to aggregate dollarization persistence.

\section{Caveat: The role of learning}

An alternative way to rationalize the fact that individuals are heterogeneous in their forecast of $R_{t}$ is to assume that they cannot perfectly observe the true process that governs the evolution of $R_{t}$. For instance, because they do not know the exact value of $\alpha$ in (3). In this case, individuals should form priors on the value of this parameter in order to forecast $R_{t}$ and to make their portfolio choices. Agents may have different priors on $\alpha$, but they can update those priors as new information on $R_{t}$ arrives. $^{36}$

This assumption is plausible in circumstances where the central bank does not have an explicit inflation target or it has one that is not perfectly credible, for instance because it attempts to stabilize simultaneously the exchange rate and the inflation rate. Uncertainty of this type may induce positive expected values for $R_{t}$, since some agents might expect higher levels of inflation, making more profitable to invest in dollar assets.

\footnotetext{
35 The same conclusion holds when we analyze the parameterized distributions.

${ }^{36}$ For models with learning and heterogenous priors, see Arifovic (1996) and Marimón et. al (2004).
} 
Consider a common signal, $S_{i t}=S_{t}=R_{t}+\varepsilon_{t}$ where $\varepsilon_{t} \sim \operatorname{iid}\left(0, \sigma_{\varepsilon}^{2}\right)$ is an aggregate shock. Under this type of uncertainty, the perceived law of motion for $R_{t}$ of individual $i$, becomes

$$
\hat{r}_{i t+1}=\mu\left(1-\hat{\alpha}_{i t}\right)+\hat{\alpha}_{i t} \hat{r}_{i t}+\omega_{t}
$$

Although every agent faces the same signal extraction problem, they portfolio choices differ since they have different priors of $\alpha$. In this case the optimal portfolio allocation for individual $i$ would be given by

$$
x_{i t}=\hat{\alpha}_{i t} x_{i t-1}+\frac{\mu}{v}+\hat{\alpha}_{i t}\left(\frac{\sigma_{\varepsilon}^{2}}{v_{i}+\sigma_{\varepsilon}^{2}}\right) \xi_{i, t}
$$

where $\xi_{i, t}=\varepsilon_{t}+R_{t}-\hat{r}_{i t}$. Notice that the implications for aggregation and heterogeneity are different in this case to those obtained in the baseline model. Here, all agents have the same ability to extract information, but they differ on their priors on $\alpha$. Since, agents update their beliefs as new information arrives, heterogeneity is not a permanent or structural feature, it only lasts while agents learn the true value of $\alpha$.

This fact have remarkable implications, but complicates considerably the empirical implementation of model. Firstly, the degree of aggregate persistence would decrease as agents learn, since the dispersion on the values of $\hat{\alpha}_{i t}$ would decrease, therefore, the coefficients of equation (11) would be time varying. Although the available sample used in the empirical analysis is relatively short, no strong evidence of time varying parameters was found. Secondly, the speed of the reduction on the degree of persistence would depend on the dispersion of the initial distribution of priors on $\alpha$ : if initial dispersion is high, the reduction on the persistence would be slower. Finally, central banks that adopt a credible inflation target regime for conducting monetary policy, can help not only to reduce the mean value of dollarization but also its persistence by reducing the dispersion on the 
priors that individuals have on $\alpha$.

\section{Concluding remarks}

In countries with high dollarization ratios, participation in the dollar deposit market has become massive. Financial deregulation, liberalization, innovation and informal currency markets have allowed a very heterogenous group of agents - from a large firm that uses state-of-art portfolio management techniques to uninformed individuals who base their portfolio decisions simply on their own experience and limited information - to participate in the same market. This paper shows that such an heterogeneity turns out to be enough to generate persistence in dollarization ratios upon aggregation. Empirical evidence from three Latin American countries and Poland supports this claim.

The presence of heterogeneity in individual dollarization decisions has interesting policy implications. Ize and Levy Yeyati (2003) conclude sensibly that a necessary and sufficient condition for dedollarization is higher exchange rate flexibility. In our setup this condition is not sufficient (though we reckon it is necessary), as there may exist a mass of individuals that do not respond at all to such a volatility. This makes a case for a more active policy on improving the communication skills of the central bank, in order to better convey its policy of more flexible exchange rates and possibly its commitment to price stability to a broader set of agents, specially to those regarded as uninformed. In this way the policymaker would be contributing to reduce individual heterogeneity and thus aggregate persistence.

This policy implication is particularly relevant for developing economies with an inflation targeting regime or for those evaluating moving towards this regime, as it heavily relies upon transparency and communication strategies. Our analysis suggests that the benefits of such a policy regime in reducing 
dollarization may be condemned to be limited, unless the central bank effectively communicates the implications and benefits of such a regime to the less informed segment of participants in the dollar market.

\section{References}

Agénor, Pierre-Richard and Nadeem U. Haque, 1996, "Macroeconomic Management with Informal Financial Markets", International Journal of Finance and Economics, 1(2), 87-101.

Aoki, Kosuke, 2003, "On the Optimal Monetary Policy Response to Noisy Indicators", Journal of Monetary Economics, 50(3), 501-523.

Arifovic, Jasmina, 1996, "The Behavior of the Exchange Rate in the Genetic Algorithm and Experimental Economics", Journal of Political Economy, 104(3), 510-541.

Baillie, Richard, 1996, "Long Memory Processes and Fractional Integration in Econometrics", Journal of Econometrics, 73(1), 5-59.

Calvo, Guillermo A. and Carmen M. Reinhart, 2002, "Fear of Floating", Quarterly Journal of Economics, 107(2), 379-408.

Céspedes, Luis F., Roberto Chang and Andrés Velasco, 2004, "Balance Sheets and Exchange Rate Policy", American Economic Review, 94(4), 1183-1193.

Cook, David, 2004, "Monetary Policy in Emerging Markets: Can Liability Dollarization Explain Contractionary Devaluations?", Journal of Monetary Economics, 51(6), 1155-1181.

De Nicoló, Gianni, Patrick Honohan and Alain Ize, 2005, "Dollarization of Bank Deposits: Causes and Consequences", Journal of Banking and Finance, 29(7), 1697-1727.

Granger, Clive W. J., 1980, "Long Memory Relationships and the Aggregation of Dynamic Models", Journal of Econometrics, 14(2), 227-238.

Guidotti, Pablo E. and Carlos A. Rodríguez, 1992, "Dollarization in Latin America: Gresham's Law in Reverse?", IMF Staff Papers, 39(3), 518-544.

Harvey, Andrew C., 1989, Forecasting, Structural Time Series Models and the Kalman Filter, Cambridge University Press.

Harvey, Andrew C. and Giuliano De Rossi, 2006, "Signal extraction”, ch. 31 in Mills, Terence C. and Kerry Patterson (eds.), Palgrave Handbook of Econometrics, Palgrave Macmillan.

Ize, Alain and Eduardo Levy Yeyati, 2003, "Financial Dollarization”, Journal of International Economics, 59(2), 323-347. 
Kamin, Steven B. and Neil R. Ericsson, 2003, "Dollarization in Post-Hyperinflationary Argentina", Journal of International Money and Finance, 22(2), 185-211.

Levy Yeyati, Eduardo, 2006, "Financial Dollarization: Evaluating the Consequences", Economic Policy, 21(45), 61-118.

Lewbel, Arthur, 1994, "Aggregation and Simple Dynamics", American Economic Review, 84(4), 905-918.

Ljungqvist, Lars and Thomas J. Sargent, 2000, Recursive Macroeconomic Theory, MIT Press.

Marimóm, Ramón, Ellen McGrattan and Thomas J. Sargent, 2004, "Money as Medium of Exchange in an Economy with Artificially Intelligent Agents", Journal of Economics Dynamics and Control, 14(2), 329373.

Michelacci, Claudio, 2004, "Cross-sectional Heterogeneity and the Persistence of Aggregate Fluctuations", Journal of Monetary Economics, 51(7), 1321-1352.

Morón, Eduardo and Diego Winkelried, 2005, "Monetary Policy Rules for Financially Vulnerable Economies", Journal of Development Economics, 76(1), 23-51.

Pesaran, M. Hashem, 2003, "Aggregation of Linear Dynamic Models: An Application to Life-Cycle Consumption Models under Habit Formation”, Economic Modelling, 20(2), 383-415.

Quispe, Zenón, 2000, "Monetary Policy in a Dollarised Economy: the Case of Peru", in Mahadeva, Lavan and Gabriel Sterne (eds.), Monetary Policy Frameworks in a Global Context, Routledge \& Bank of England, London-New York.

Reinhart, Carmen M., Kenneth S. Rogoff and Miguel A. Savastano, 2003, "Addicted to Dollars", NBER Working Paper No. 10015.

Savastano, Miguel A., 1996, "Dollarization in Latin America. Recent Evidence and some Policy Issues", in Paul Mizen and Eric J. Pentecost (eds.), The Macroeconomics of International Currencies: Theory, Policy, Evidence, NH: Edward Elgar.

Sims, Christopher A., 2003, "Implications of Rational Inattention”, Journal of Monetary Economics, 50(3), 665-690.

Sturzenegger, Federico, 1997, "Understanding the Welfare Implications of Currency Substitution", Journal of Economic Dynamics and Control, 21(2/3), 391-416.

Uribe, Martín, 1997, "Hysteresis in a Simple Model of Currency Substitution", Journal of Monetary Economics, 40(1), 185-202.

Zaffaroni, Paolo, 2004, "Contemporaneous Aggregation of Linear Dynamic Models in Large Economies", Journal of Econometrics, 120(1), 75-102. 


\section{A Aggregation}

The derivations herein follow Lewbel (1994) closely. To alleviate the notation we drop the $i$ subscript in this appendix.

\section{A.1 Equations (11) and (12)}

Consider equation (10),

$$
x_{t}=a x_{t-1}+c+u_{t}
$$

where $u_{t}=b S_{t}$. Note that $c$ and $u_{t}$ are individual specific and hence depend on $a$. Since by assumption $S_{t}$ is a sequence of serially uncorrelated shocks, so is $u_{t}$.

Let $E_{a}$ be the expectation operator across individuals, $E_{a}[z]=\int z \mathrm{~d} F(a)$, such that $X_{t}=E_{a}\left[x_{t}\right]$, $C=E_{a}[c]$ and $U_{t}=E_{a}\left[u_{t}\right]$. Aggregation of (A1) renders

$$
X_{t}=E_{a}\left[a x_{t-1}\right]+C+U_{t}
$$

Define a random variable $\alpha_{s}$, a scalar $A_{s}=E_{a}\left[\alpha_{s}\right]$ and a recursion $\alpha_{s+1}=\left(\alpha_{s}-A_{s}\right) a$ with initial condition $\alpha_{1}=a$. Note that for $s>1$ the above recursion implies that $\alpha_{s}=a^{s}-\sum_{j=1}^{s-1} a^{s-j} A_{r}$. After taking $E_{a}$ expectations we get equation (12) in the main text, where $m_{s}=E_{a}\left[a^{s}\right]$ is the $s$-th moment of the distribution of $a$. Note also that

$$
\begin{aligned}
E_{a}\left[\alpha_{s} x_{t-s}\right] & =A_{s} X_{t-s}+E_{a}\left[\left(\alpha_{s}-A_{s}\right) x_{t-s}\right] \\
& =A_{s} X_{t-s}+E_{a}\left[\left(\alpha_{s}-A_{s}\right) a x_{t-(s+1)}\right]+E_{a}\left[\left(\alpha_{s}-A_{s}\right) c\right]+E_{a}\left[\left(\alpha_{s}-A_{s}\right) u_{t-s}\right] \\
& =A_{s} X_{t-s}+E_{a}\left[\alpha_{s+1} x_{t-(s+1)}\right]+\operatorname{cov}\left(\alpha_{s}, c\right)+\operatorname{cov}\left(\alpha_{s}, u_{t-s}\right)
\end{aligned}
$$

where $\operatorname{cov}\left(\alpha_{s}, c\right)$ is the cross-sectional covariance of $\alpha_{s}$ and $c$ which is time-invariant. On the other side, $\operatorname{cov}\left(\alpha_{s}, u_{t-s}\right)$ is the cross-sectional covariance of $\alpha_{s}$ and $u_{t-s}$ which is time dependent, but as this dependency comes from $S_{t}$, it is serially uncorrelated.

Equation (A3) shows a recursion between $E_{a}\left[\alpha_{s} x_{t-s}\right]$ and $E_{a}\left[\alpha_{s+1} x_{t-(s+1)}\right]$. After solving it,

$$
E_{a}\left[a x_{t-1}\right]=\sum_{j=1}^{\infty} A_{j} X_{t-j}+\sum_{j=1}^{\infty} \operatorname{cov}\left(\alpha_{j}, c\right)+\sum_{j=1}^{\infty} \operatorname{cov}\left(\alpha_{j}, u_{t-j}\right)
$$


Let $V_{t}=\sum_{j=1}^{\infty} \operatorname{cov}\left(\alpha_{j}, u_{t-j}\right)$ and $\tilde{V}=E\left[V_{t}\right]$, where $E$ is the expectation operator over time. Define also $\tilde{C}=C+\sum_{j=1}^{\infty} \operatorname{cov}\left(\alpha_{j}, c\right)+\tilde{V}$ and $\tilde{U}_{t}=U_{t}+V_{t}-\tilde{V}$. Then, after plugging (A4) into (A2) we get equation (11) in the main text, $X_{t}=\sum_{j=1}^{\infty} A_{j} X_{t-j}+\tilde{C}+\tilde{U}_{t}$, where $\tilde{U}_{t}$ is serially uncorrelated. ${ }^{37}$ The underlying assumptions behind the aggregate equation (11) are thus, that $\tilde{C}$ and $V_{t}$ are both finite or the sequences $\left\{\operatorname{cov}\left(\alpha_{j}, c\right)\right\}_{j=1}^{\infty}$ and $\left\{\operatorname{cov}\left(\alpha_{j}, u_{t-j}\right)\right\}_{j=1}^{\infty}$ are absolute summable.

\section{A.2 Equation (14)}

Consider now equation (A1) in first differences

$$
\Delta x_{t}=a \Delta x_{t-1}+u_{t}-u_{t-1}
$$

so that after aggregation, $\Delta X_{t}=E_{a}\left[a \Delta x_{t-1}\right]+U_{t}-U_{t-1}$. Following the same procedure leading to equation (A4),

$$
E_{a}\left[a \Delta x_{t-1}\right]=\sum_{j=1}^{\infty} A_{j} \Delta X_{t-j}+V_{t}-V_{t-1}
$$

so that $\Delta X_{t}$ can be written as

$$
\Delta X_{t}=\sum_{j=1}^{\infty} A_{j} \Delta X_{t-j}+\left(U_{t}+V_{t}\right)-\left(U_{t-1}+V_{t-1}\right)=\sum_{j=1}^{\infty} A_{j} \Delta X_{t-r}+U_{t}^{\dagger}
$$

which corresponds to the first-difference version or (11). The new aggregate error $U_{t}^{\dagger}$ is serially correlated and the coefficients are the same as those in (11).

\section{A.3 Equation (13)}

All the results derived above go through straightforwardly when $S_{t}=R_{t}+\varepsilon_{t}$ where $\varepsilon_{t}$ is iid. Coefficients $a$ and $b$ and the noise $\varepsilon_{t}$ are individual specific whereas $R_{t}$ is an aggregate figure, so $X_{t}=E_{a}\left[a x_{t-1}\right]+E_{a}[b] R_{t}+E_{a}\left[b \varepsilon_{t}\right]$. Equation (A4) is now

$$
E_{a}\left[a x_{t-1}\right]=\sum_{j=1}^{\infty} A_{j} X_{t-j}+\sum_{j=1}^{\infty} \operatorname{cov}\left(\alpha_{j}, c\right)+\sum_{j=1}^{\infty} \operatorname{cov}\left(\alpha_{j}, b\right) R_{t}+\sum_{j=1}^{\infty} \operatorname{cov}\left(\alpha_{j}, b \varepsilon_{t}\right)
$$

\footnotetext{
$\overline{37}$ Pesaran (2003) shows that it is heteroscedastic, though.
} 
Call $B_{0}=E_{a}[b], B_{j}=\operatorname{cov}\left(\alpha_{j}, b\right), \hat{U}_{t}=\sum_{j=0}^{\infty} W_{t-j}$ where $W_{t}=\sum_{j=1}^{\infty} \operatorname{cov}\left(\alpha_{j}, b \varepsilon_{t}\right)$. Further mechanical manipulation leads to (13). The aggregate disturbance $\hat{U}_{t}$ is serially correlated.

\section{B A brief note on fractional integration}

Consider the univariate dynamic model

$$
\Phi(L)(1-L)^{d} X_{t}=\Theta(L) \eta_{t}
$$

where $L$ is the lag operator, $\eta_{t} \sim \operatorname{iid}\left(0, \sigma_{\eta}^{2}\right)$ and $d$ is the differencing parameter. When $d=0, X_{t}$ is stationary and follows an ARMA process, $\Phi(L) X_{t}=\Theta(L) \eta_{t}$. When $d=1, X_{t}$ has a unit root and hence follows an ARIMA process, $\Phi(L) \Delta X_{t}=\Theta(L) \eta_{t}$. More generally, when $d$ takes non-integer values, $X_{t}$ is said to be a fractionally integrated ARMA (ARFIMA) process. When $d \in(0,0.5]$, the autocovariance function of $X_{t}$ declines hyperbolically to zero, making $X_{t}$ a stationary long-memory process. For $d>0.5, X_{t}$ is non-stationary (has infinite variance).

Granger (1980) has shown that under particular assumptions about $F(a)$ - the distribution of individual autoregressive coefficients - the aggregation of AR(1) processes like (10) leads to (B1). ${ }^{38}$ In our empirical application, we simply imposed $d=1$ and proceeded. If $d<1$ truly, then we would have over-differentiated the data, with possible negative effects in our statistical inference.

Table B1 displays estimates of $d$ and tests $H_{0}: d=0$ and $H_{0}: d=1$. We did not find enough evidence to reject $H_{0}: d=1$ whereas $H_{0}: d=0$ is systematically rejected.

Table B1. Estimated fractional integration parameter in dollarization ratios

\begin{tabular}{lccccr}
\hline & & \multicolumn{2}{c}{$H_{0}: d=0$} & \multicolumn{2}{c}{$H_{0}: d=1$} \\
& $\hat{d}$ & $t$-stat & $p$-value & $t$-stat & $p$-value \\
\hline Mexico & 0.825 & 2.376 & 0.0491 & 0.505 & 0.6294 \\
Peru & 0.932 & 3.883 & 0.0037 & 0.282 & 0.7843 \\
Poland & 0.955 & 4.605 & 0.0025 & 0.219 & 0.8333 \\
Uruguay & 0.788 & 2.485 & 0.0378 & 0.667 & 0.5236 \\
\hline
\end{tabular}

The estimation method is that of Geweke and Porter-Hudak (known as GPH). The asymptotic standard error of $\hat{d}$ is $\pi^{2} / 6$ which is used to compute the $t$-statistics and $p$-values. Both tests $\left(H_{0}: d=0\right.$ and $\left.H_{0}: d=1\right)$ are two-tailed. See Baillie (1996) for a review of ARFIMA modelling and for critics to the GPH estimator.

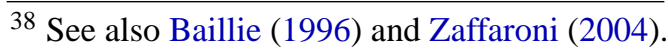




\section{The distribution of endowments and abilities}

Our results were derived under the assumption that agents are homogenous in their endowments. In particular, we restricted the analysis to the case where each agent has an endowment of size one. Here, we show that our results hold for a more general case, one in which agents have different size of endowments, but where the distribution of abilities $\left(a_{i}\right)$ across agents is correlated with that of the endowments. We regard this correlation as plausible in reality.

Consider equation (10). For the sake of argument, set $\mu=0$ so $c_{i}=0$, define $u_{i t}=b_{i} S_{i t}$ and assume that aggregate income is equal to one and that there are two agents in the economy: one with ability $a_{1}$ and income $n_{1}$ and the other with ability $a_{2}$ and income $n_{2}=1-n_{1}$. Then,

$$
\left(1-a_{i} L\right) x_{i t}=u_{i t} \quad \text { for } i=1,2
$$

After generating a common lag polynomial for both processes we have that

$$
\left(1-a_{j} L\right)\left(1-a_{i} L\right) x_{i t}=\left(1-a_{j} L\right) u_{i t} \quad \text { for } i=1,2 \text { and } i \neq j
$$

The aggregate level of dollar deposits, which coincides with the aggregate dollarization ratio, is $X_{t}=n_{1} x_{1 t}+n_{2} x_{2 t}$. Aggregate the equations in (C2) to get

$$
\left(1-a_{1} L\right)\left(1-a_{2} L\right) X_{t}=n_{1}\left(1-a_{2} L\right) u_{1 t}+n_{2}\left(1-a_{1} L\right) u_{2 t}
$$

Define $\tilde{u}_{i t}=n_{i} u_{i t}$ for $i=1,2$. Then, (C3) boils down to

$$
X_{t}=\left(a_{1}+a_{2}\right) X_{t-1}+a_{1} a_{2} X_{t-2}+\tilde{u}_{1 t}-a_{2} \tilde{u}_{1 t-1}+\tilde{u}_{2 t}-a_{1} \tilde{u}_{2 t-1}
$$

We have that if $S_{t}$ is an iid sequence, the aggregate dollarization ratio follows an ARMA(2,1) process. This simple example can be generalizad to the case of $N \operatorname{AR}(1)$ process (hence $N$ ability or endowment levels); in such a case the aggregate dollarization ratio follows an $\operatorname{ARMA}\left(N^{*}, N^{*}-1\right)$ process, where $N^{*} \leq N$. We can increase the number of agents involved by simply replicating the individual behavior for a given ability $a$ an arbitrary number of times. Therefore, the aggregation results derived in appendix A go through under the assumption that the distribution of endowments is correlated to that of the abilities to process information. When $N \rightarrow \infty$, we get the limiting case exposed in appendix B. These derivations apply straightforwardly to the alternative case where $S_{i t}$ is not iid. 


\section{Figure 1. Deposit Dollarization in Peru}

(a) Dollar deposits to M2

(1990 - 2005)

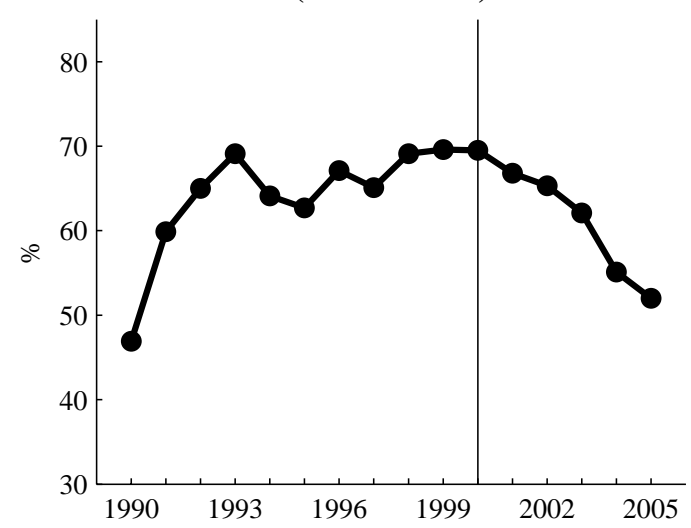

(b) Dollarization of banking deposits (2000 - 2005)

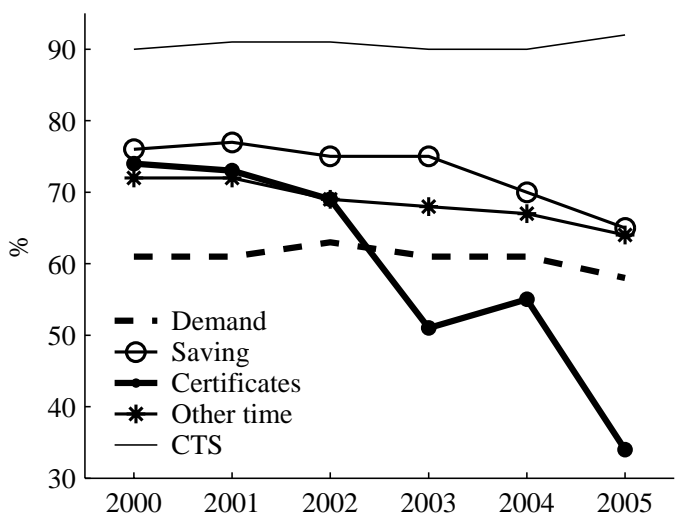

Source: Central Bank of Peru.

Figure 2. Deposit Dollarization in Poland

(a) Dollar deposits to M2

(1985-2001)

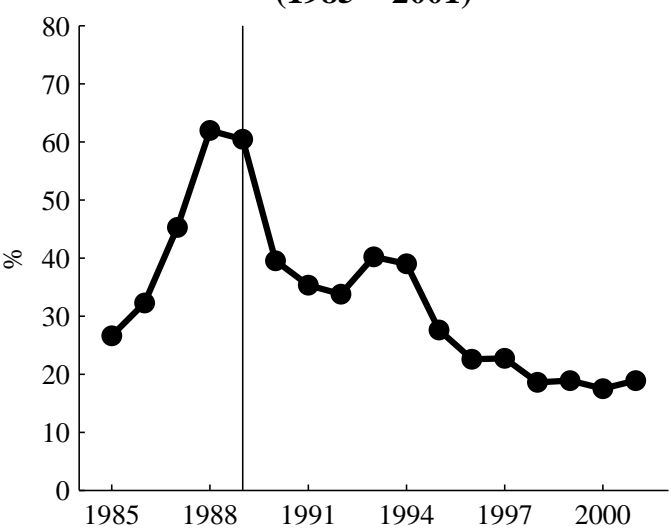

(b) Dollarization of banking deposits (1993 - 2001)

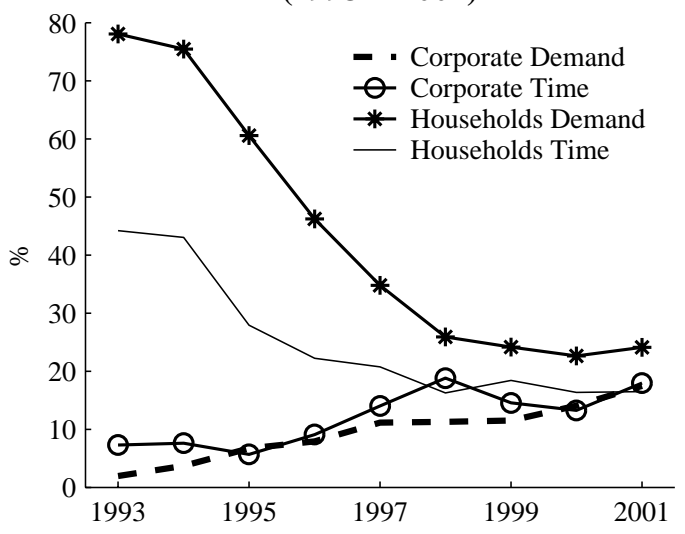

Source: National Bank of Poland. 
Table 1. ARIMA models of the deposit dollarization ratio in selected countries

\begin{tabular}{|c|c|c|c|c|c|c|c|}
\hline ARIMA model & $A_{1}$ & $A_{2}$ & $A_{3}$ & $A_{4}$ & $\theta$ & $A_{3}-A_{1} A_{2}$ & $\bar{R}^{2}$ \\
\hline \multicolumn{8}{|c|}{ Mexico (1985.Q4 to 2005.Q3, $N=77$ ) } \\
\hline \multirow[t]{2}{*}{$(4,1,0)$} & $0.221^{*}$ & $0.199^{*}$ & $-0.192^{*}$ & $0.114^{* *}$ & & $-0.236^{*}$ & 0.221 \\
\hline & $(0.078)$ & $(0.078)$ & $(0.072)$ & $(0.064)$ & & $(0.095)$ & \\
\hline \multirow[t]{2}{*}{$(4,1,1)^{\star}$} & $0.480^{*}$ & $0.195^{*}$ & $-0.216^{*}$ & $0.251^{*}$ & $-0.097^{*}$ & $-0.310^{*}$ & 0.261 \\
\hline & $(0.111)$ & $(0.094)$ & $(0.063)$ & $(0.047)$ & $(0.018)$ & $(0.086)$ & \\
\hline \multicolumn{8}{|c|}{ Peru (1980.Q1 to $2005 . \mathrm{Q} 3, N=94)$} \\
\hline \multirow[t]{2}{*}{$(2,1,0)^{\star}$} & $0.173^{*}$ & $0.142^{*}$ & & & & $-0.024^{* *}$ & 0.200 \\
\hline & $(0.063)$ & $(0.058)$ & & & & $(0.013)$ & \\
\hline \multirow[t]{2}{*}{$(2,1,1)$} & $0.186^{* *}$ & $0.139^{*}$ & & & -0.058 & -0.026 & 0.173 \\
\hline & $(0.094)$ & $(0.065)$ & & & $(0.143)$ & $(0.016)$ & \\
\hline \multicolumn{8}{|c|}{ Poland (1985.Q4 to 2002.Q4, $N=69$ ) } \\
\hline \multirow[t]{2}{*}{$(2,1,0)^{\star}$} & $0.474^{*}$ & $0.113^{*}$ & & & & $-0.053^{*}$ & 0.215 \\
\hline & $(0.016)$ & $(0.052)$ & & & & $(0.024)$ & \\
\hline \multirow[t]{2}{*}{$(2,1,1)$} & $0.476^{*}$ & $0.111^{*}$ & & & -0.007 & $-0.053^{*}$ & 0.275 \\
\hline & $(0.010)$ & $(0.049)$ & & & $(0.045)$ & $(0.024)$ & \\
\hline \multicolumn{8}{|c|}{ Uruguay (1985.Q1 to 2005.Q3, $N=83$ ) } \\
\hline \multirow[t]{2}{*}{$(2,1,0)$} & $0.218^{*}$ & $0.290^{*}$ & & & & $-0.063^{*}$ & 0.153 \\
\hline & $(0.091)$ & $(0.116)$ & & & & $(0.029)$ & \\
\hline \multirow[t]{2}{*}{$(2,1,1)^{\star}$} & $0.265^{* *}$ & $0.215^{*}$ & & & $-0.093^{*}$ & $-0.057^{* *}$ & 0.196 \\
\hline & $(0.147)$ & $(0.055)$ & & & $(0.034)$ & $(0.033)$ & \\
\hline
\end{tabular}

Maximum likelihood estimates. Figures in parentheses are robust (consistent) standard errors. * [**] denotes significance at a $5 \%[10 \%]$ level. The standard error of the third central moment $A_{3}-A_{1} A_{2}$ was computed with the delta method. $\bar{R}^{2}$ is the adjusted $R^{2}$. Regressions include a constant and, if necessary, a few dummy variables for outlier removal. In all reported equations, Breusch-Godfrey and Jarque-Bera tests suggested uncorrelated and normally distributed residuals. The preferred specifications are marked with a $\star$. 
Table 2. Augmented equations

\begin{tabular}{|c|c|c|c|c|c|c|c|}
\hline & $A_{1}$ & $A_{2}$ & $A_{3}$ & $A_{3}-A_{1} A_{2}$ & $H_{0}: B=0$ & $p_{R}$ & $\bar{R}^{2}$ \\
\hline \multicolumn{8}{|c|}{ Mexico $(1985 . \mathrm{Q} 4$ to $2005 . \mathrm{Q} 3, N=77)$} \\
\hline ex-ante & $\begin{array}{l}0.391^{*} \\
(0.096)\end{array}$ & $\begin{array}{l}0.202^{*} \\
(0.066)\end{array}$ & $\begin{array}{c}-0.273^{*} \\
(0.092)\end{array}$ & $\begin{array}{c}-0.331^{*} \\
(0.113)\end{array}$ & $\begin{array}{l}11.50^{*} \\
{[0.000]}\end{array}$ & 2 & 0.554 \\
\hline ex-post & $\begin{array}{c}0.229 \\
(0.201)\end{array}$ & $\begin{array}{l}0.287^{*} \\
(0.089)\end{array}$ & $\begin{array}{c}-0.240^{*} \\
(0.080)\end{array}$ & $\begin{array}{c}-0.278^{*} \\
(0.091)\end{array}$ & $\begin{array}{l}22.56^{*} \\
{[0.000]}\end{array}$ & 2 & 0.565 \\
\hline \multicolumn{8}{|c|}{ Peru (1980.Q1 to 2005.Q3, $N=89$ ) } \\
\hline ex-ante & $\begin{array}{l}0.242^{*} \\
(0.043)\end{array}$ & $\begin{array}{l}0.195^{*} \\
(0.047)\end{array}$ & $\begin{array}{c}0.003 \\
(0.053)\end{array}$ & $\begin{array}{c}-0.047^{*} \\
(0.015)\end{array}$ & $\begin{array}{l}9.086^{*} \\
{[0.000]}\end{array}$ & 3 & 0.435 \\
\hline ex-post & $\begin{array}{l}0.501^{*} \\
(0.098)\end{array}$ & $\begin{array}{c}0.138^{* *} \\
(0.083)\end{array}$ & $\begin{array}{l}-0.027 \\
(0.068)\end{array}$ & $\begin{array}{c}-0.069^{* *} \\
(0.036)\end{array}$ & $\begin{array}{l}30.85^{*} \\
{[0.000]}\end{array}$ & 2 & 0.649 \\
\hline \multicolumn{8}{|c|}{ Poland (1985.Q4 to 2005.Q3, $N=68$ ) } \\
\hline ex-ante & $\begin{array}{l}0.449^{*} \\
(0.043)\end{array}$ & $\begin{array}{l}0.132^{*} \\
(0.058)\end{array}$ & $\begin{array}{c}-0.002 \\
(0.049)\end{array}$ & $\begin{array}{c}-0.059^{*} \\
(0.022)\end{array}$ & $\begin{array}{c}1.638 \\
{[0.203]}\end{array}$ & 3 & 0.275 \\
\hline ex-post & $\begin{array}{l}0.586^{*} \\
(0.077)\end{array}$ & $\begin{array}{l}0.164^{*} \\
(0.070)\end{array}$ & $\begin{array}{c}-0.123 \\
(0.160)\end{array}$ & $\begin{array}{c}-0.096^{*} \\
(0.043)\end{array}$ & $\begin{array}{c}2.402^{* *} \\
{[0.099]}\end{array}$ & 4 & 0.394 \\
\hline \multicolumn{8}{|c|}{ Uruguay (1985.Q1 to $2005 . \mathrm{Q} 3, N=80$ ) } \\
\hline ex-ante & $\begin{array}{l}0.252^{*} \\
(0.104)\end{array}$ & $\begin{array}{l}0.280^{*} \\
(0.114)\end{array}$ & $\begin{array}{c}-0.109 \\
(0.140)\end{array}$ & $\begin{array}{c}-0.070^{\text {** }} \\
(0.038)\end{array}$ & $\begin{array}{l}3.153^{*} \\
{[0.049]}\end{array}$ & 3 & 0.124 \\
\hline ex-post & $\begin{array}{l}0.267^{*} \\
(0.103)\end{array}$ & $\begin{array}{l}0.349^{*} \\
(0.117)\end{array}$ & $\begin{array}{c}-0.073 \\
(0.143)\end{array}$ & $\begin{array}{c}-0.093^{* *} \\
(0.047)\end{array}$ & $\begin{array}{c}2.189 \\
{[0.119]}\end{array}$ & 2 & 0.152 \\
\hline
\end{tabular}

2SLS estimates. Instruments for $R_{t}^{D}$ and $R_{t}^{P}$ (and for the ex-ante $R_{t-1}^{D}$ and $R_{t-1}^{P}$ ) are oil prices changes, US GDP growth and lagged values of these and the $R$-variables. Figures in parentheses are robust (consistent) standard errors. * [**] denotes significance at a 5\% [10\%] level. Figures in the $H_{0}: B=0$ column are $F$-statistics, $p$-values shown in braces. For Peru, Poland and Uruguay, we set $A_{3}=0$ to compute the third central moment and its standard deviation. Diagnostic tests suggested well-behaved residuals, see notes to Table 1. 


\section{Documentos de Trabajo publicados \\ Working Papers published}

La serie de Documentos de Trabajo puede obtenerse de manera gratuita en formato pdf en la siguiente dirección electrónica:

http://www.bcrp.gob.pe/bcr/index.php?Itemid=213

The Working Paper series can be downloaded free of charge in pdf format from:

http://www.bcrp.gob.pe/bcr/ingles/index.php?/temid=104

2007

\section{Marzo I March}

DT N 2007-003

Why Central Banks Smooth Interest Rates?: A Political Economy Explanation

Carlos Montoro

\section{Febrero I February}

DT $\mathrm{N}^{\circ} 2007-002$

Comercio y crecimiento: Una revisión de la hipótesis "Aprendizaje por las

Exportaciones"

Raymundo Chirinos Cabrejos

\section{Enero I January}

DT N²007-001

Perú: Grado de inversión, un reto de corto plazo

Gladys Choy Chong

\section{6}

\section{Octubre I October}

DT N²006-010

Dolarización financiera, el enfoque de portafolio y expectativas:

Evidencia para América Latina (1995-2005)

Alan Sánchez

DT N²006-009

Pass-through del tipo de cambio y política monetaria:

Evidencia empírica de los países de la OECD

César Carrera, Mahir Binici

\section{Agosto \ August}

DT No2006-008

Efectos no lineales de choques de política monetaria y de tipo de cambio real en economías parcialmente dolarizadas: un análisis empírico para el Perú

Saki Bigio, Jorge Salas 


\section{Junio I June}

DT N ${ }^{\circ} 2006-007$

Corrupción e Indicadores de Desarrollo: Una Revisión Empírica

Saki Bigio, Nelson Ramírez-Rondán

DT N ${ }^{\circ} 2006-006$

Tipo de Cambio Real de Equilibrio en el Perú: modelos BEER y construcción de bandas de confianza

Jesús Ferreyra y Jorge Salas

DT N 2006-005

Hechos Estilizados de la Economía Peruana

Paul Castillo, Carlos Montoro y Vicente Tuesta

DT N²006-004

El costo del crédito en el Perú, revisión de la evolución reciente

Gerencia de Estabilidad Financiera

DT N 2006-003

Estimación de la tasa natural de interés para la economía peruana

Paul Castillo, Carlos Montoro y Vicente Tuesta

\section{Mayo I May}

DT N² 2006-02

El Efecto Traspaso de la tasa de interés y la política monetaria en el Perú: 1995-2004 Alberto Humala

\section{Marzo I March}

DT N²006-01

¿Cambia la Inflación Cuando los Países Adoptan Metas Explícitas de Inflación?

Marco Vega y Diego Winkelreid

2005

\section{Diciembre I December}

DT N 2005-008

El efecto traspaso de la tasa de interés y la política monetaria en el Perú 1995-2004 Erick Lahura

\section{Noviembre I November}

DT N $\mathrm{N}^{\circ} 2005-007$

Un Modelo de Proyección BVAR Para la Inflación Peruana

Gonzalo Llosa, Vicente Tuesta y Marco Vega

DT N²005-006

Proyecciones desagregadas de la variación del Índice de Precios al Consumidor (IPC), del Índice de Precios al Por Mayor (IPM) y del Crecimiento del Producto Real (PBI)

Carlos R. Barrera Chaupis 


\section{Marzo I March}

DT N²005-005

Crisis de Inflación y Productividad Total de los Factores en Latinoamérica Nelson Ramírez Rondán y Juan Carlos Aquino.

DT N 2005-004

Usando información adicional en la estimación de la brecha producto en el Perú: una aproximación multivariada de componentes no observados

Gonzalo Llosa y Shirley Miller.

DT No2005-003

Efectos del Salario Mínimo en el Mercado Laboral Peruano

Nikita R. Céspedes Reynaga

\section{Enero I January}

DT $\mathrm{N}^{\circ} 2005-002$

Can Fluctuations in the Consumption-Wealth Ratio Help to Predict Exchange Rates? Jorge Selaive y Vicente Tuesta

DT N ${ }^{\circ} 2005-001$

How does a Global disinflation drag inflation in small open economies?

Marco Vega y Diego Winkelreid 